\title{
Electrodiagnostic Testing and Treatment for Carpal Tunnel Syndrome in Canada
}

\author{
Rodney Li Pi Shan, Michael Nicolle, Ming Chan, Nigel Ashworth, Chris White, \\ Paul Winston, Sean Dukelow
}

\begin{abstract}
Objectives: 1) Assess which electrodiagnostic studies Canadian clinicians use to aid in the diagnosis of carpal tunnel syndrome (CTS). 2) Assess whether Canadian clinicians follow the American Association of Neuromuscular \& Electrodiagnostic Medicine/ American Academy of Neurology/American Academy of Physical Medicine and Rehabilitation Practice Parameter for Electrodiagnostic Studies in CTS. 3) Assess how Canadian clinicians manage CTS once a diagnosis has been established. Methods: In this prospective observational study, an electronic survey was sent to all members of the Canadian Neuromuscular Group (CNMG) and the Canadian Association of Physical Medicine and Rehabilitation (CAPM\&R) Neuromuscular Special Interest Group. Questions addressed which electrodiagnostic tests were being routinely used for the diagnosis of carpal tunnel syndrome. Management recommendations for CTS was also explored. Results: Of the 70 individuals who completed the survey, fourteen different nerve conduction study techniques were reported. Overall, 36/70 (51\%) of participants followed the AANEM/AAN/AAPM\&R Practice Parameter. The standard followed by the fewest of our respondents with 64\% compliance (45/70) was the use of a standard distance of 13 to $14 \mathrm{~cm}$ with respect to the median sensory nerve conduction study. Regarding management, $99 \%$ would recommend splinting in the case of mild CTS. In moderate CTS, splinting was recommended by $91 \%$ of clinicians and $68 \%$ would also consider referral for surgery. In severe CTS, most recommended surgery ( $93 \%$ ). Conclusions: There is considerable variability in terms of which electrodiagnostic tests Canadian clinicians perform for CTS. Canadian clinicians are encouraged to adhere to the AANEM/AAN/AAPM\&R Practice Parameter for Electrodiagnostic Studies in CTS.
\end{abstract}

RÉSUMÉ: Électrodiagnostic et traitement du syndrome du canal carpien au Canada. Objectifs: 1) Évaluer quelles études électrodiagnostiques sont utilisées par les cliniciens canadiens pour diagnostiquer le syndrome du canal carpien (SCC); 2) Évaluer si les cliniciens canadiens suivent les guides de pratiques de l'American Association of Neuromuscular \& Electrodiagnostic Medicine/American Academy of Neurology/American Academy of Physical Medicine and Rehabilitation Practice Parameter for Electrodiagnostic Studies (AANEM/AAN/AAPM\&R) concernant le SCC; 3 ) Évaluer comment les cliniciens canadiens traitent le SCC lorsque le diagnostic est posé. Méthode: Il s'agit d'une étude observationnelle prospective effectuée au moyen d'une enquête électronique auprès de tous les membres du Réseau canadien sur les maladies neuromusculaires (RCMN) et du groupe d'intérêt particulier de l'Association canadienne de médecine physique et de réadaptation (ACMP\&R). Les questions portaient sur les tests électrodiagnostiques utilisés couramment pour poser le diagnostic de SCC. Les recommandations de traitement du SCC ont également été examinées. Résultats: Soixante-dix individus ont complété le questionnaire et ont rapporté l'utilisation de quatorze techniques différentes d'étude de la conduction nerveuse. En tout, 36 des participants (51\%) suivaient les recommandations de pratique de l'AANEM/AAN/AAPM\&R. L'utilisation d'une distance standard de 13 à $14 \mathrm{~cm}$ pour l'étude de la conduction sensitive au niveau du nerf médian était suivie par le plus petit nombre de nos répondants, soit 64\% (45/70) qui rapportaient se conformer à ce standard. En ce qui concerne le traitement, $99 \%$ recommanderaient le port d'une attelle dans les cas de SCC léger. Chez les cas de SCC modéré, l'attelle était recommandée par $91 \%$ des cliniciens et $68 \%$ considéraient également référer le patient en chirurgie. Dans les cas de SCC sévère, la plupart recommandaient la chirurgie (93\%). Conclusions: Chez les cliniciens canadiens, il existe une variabilité considérable quant à l'électrodiagnostic du SCC. Les cliniciens canadiens sont encouragés à adhérer aux paramètres de pratique concernant électrodiagnostic du SCC émis par l'AANEM/AAN/AAPM\&R.

Keywords: electrodiagnostic studies, electromyography

doi: $10.1017 / \operatorname{cjn} .2015 .323$

Can J Neurol Sci. 2016; 43: 178-182

Carpal tunnel syndrome (CTS) is a clinical syndrome characterized by symptoms of numbness, tingling, burning, or pain ${ }^{1}$ as a result of compression of the median nerve in the carpal tunnel.
There is a $3 \%$ prevalence in the general population ${ }^{2}$ and a $10 \%$ lifetime risk. ${ }^{3}$ Not surprisingly, it is the most common condition seen in electromyography (EMG) laboratories across Canada.

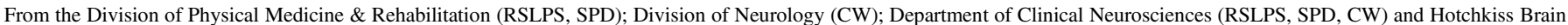
Institute (SPD, CW); Division of Physical Medicine and Rehabilitation/Department of Medicine (KMC, NLA); University of Alberta, Edmonton, Alberta; Department of Clinical

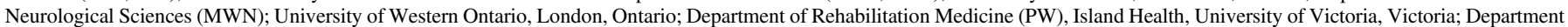
of Rehabilitation Medicine (PW), University of British Columbia, Vancouver, British Columbia, Canada.

Received OCtober 22, 2014. Final Revisions Submitted August 6, 2015.

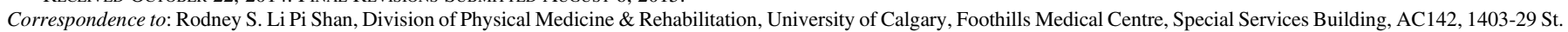
NW, Calgary, Alberta, T2N 2T9. Email: Rodney.lipishan@albertahealthservices.ca 
Patients with suspected CTS are often referred to an EMG laboratory for diagnostic confirmation and management advice. As part of the electrodiagnostic visit, a history and physical examination are done to determine the likelihood of CTS and to exclude other conditions. Although the flick sign has reasonable sensitivity $(93 \%)$ and specificity $(96 \%),{ }^{4}$ other clinical signs are modestly discriminating at best. For example, the diagnostic utility of Tinel's (sensitivity 60\%, specificity $67 \%$ ) and Phalen's (sensitivity $75 \%$, specificity $47 \%$ ) signs are relatively poor. ${ }^{5}$ The challenges associated with the clinical diagnosis of CTS support the need for electrodiagnostic studies. However, discussions with Canadian EMG physicians suggest a lack of uniformity on the extent of electrodiagnostic studies in Canadian EMG laboratories.

As the diagnostic performance of different electrodiagnostic tests varies considerably, ${ }^{6}$ a more uniform approach to the electrodiagnosis of CTS may be achieved with consensus on a minimum standard of acceptable tests. As a first step in this direction, a national survey was done to determine the variability in practice patterns across Canada. We identified which electrodiagnostic tests Canadian electromyographers used to support a diagnosis of CTS, as well as the rationale for their selections. We also examined whether commonalities exist that might allow for standardization of testing for CTS. Such standardization would lead to consistency with respect to patient care as well as ensure that clinicians are meeting a minimum benchmark for testing. Suggested benchmark guidelines include the American Association of Neuromuscular and Electrodiagnostic Medicine $\left(\right.$ AANEM) ${ }^{7}$ American Academy of Neurology (AAN), ${ }^{8}$ and American Academy of Physical Medicine and Rehabilitation (AAPM\&R) Practice Parameter for Electrodiagnostic Studies in Carpal Tunnel Syndrome.

Lastly we wished to assess how Canadian clinicians managed CTS once a diagnosis was established. In particular, we were interested in determining whether treatment recommendations differed depending on severity of the disease.

\section{MeTHODS}

\section{Laboratories Surveyed}

This prospective observational study of Canadian EMG practitioners used a web-based questionnaire to identify which electrodiagnostic studies were routinely performed to support a clinical diagnosis of CTS. In October 2012, emails sent out to all members of the Canadian Neuromuscular Group (CNMG) and members of the Canadian Association of Physical Medicine and Rehabilitation (CAPM\&R) Neuromuscular Special Interest Group contained a link to an on-line survey. This survey was comprised of 70 questions about practice patterns and routine electrodiagnostic tests performed for the suspicion of CTS. All respondents indicating that they currently saw patients in a Canadian EMG laboratory were included in the study. The study was approved by the University of Calgary Conjoint Health Research Ethics Board (CHREB).

\section{Details of the Questionnaire}

The questionnaire collected information regarding clinician demographics as well as motor, sensory, and mixed nerve conduction studies commonly performed for the diagnosis of CTS. Clinicians were asked which of these studies were done

\section{Table 1: Respondent Demographics}

\begin{tabular}{|c|c|c|}
\hline Years of Experience & $\mathbf{N}$ & Percen \\
\hline 1 to 5 & 18 & 25 \\
\hline 6 to 10 & 15 & 21 \\
\hline 11 to 15 & 13 & 18 \\
\hline 16 to 20 & 6 & 8 \\
\hline$>20$ years & 20 & 28 \\
\hline EMG Half Day Clinics Per Week & $\mathbf{N}$ & Percen \\
\hline 1 & 18 & 25 \\
\hline 2 & 23 & 32 \\
\hline 3 & 6 & 8 \\
\hline 4 & 11 & 15 \\
\hline 5 & 7 & 10 \\
\hline 6 & 3 & 4 \\
\hline 7 & 1 & 1 \\
\hline 8 & 2 & 3 \\
\hline 9 & 1 & 1 \\
\hline Province & $\mathbf{N}$ & Percen \\
\hline Alberta & 16 & 22 \\
\hline British Columbia & 15 & 21 \\
\hline Manitoba & 2 & 3 \\
\hline New Brunswick & 1 & 1 \\
\hline Nova Scotia & 1 & 1 \\
\hline Ontario & 25 & 35 \\
\hline Quebec & 8 & 11 \\
\hline Saskatchewan & 4 & 6 \\
\hline Newfoundland & 0 & 0 \\
\hline PEI & 0 & 0 \\
\hline
\end{tabular}

routinely. We also inquired what distance was used between the stimulator and the active recording electrode and whether the clinician used a fixed distance for certain studies, as some techniques in the literature ${ }^{9}$ do not. We also examined whether needle EMG was routinely done and if so, which muscles were studied. There was also an opportunity to further elaborate in an open text format on other details as to how they diagnosed CTS.

We examined what percentage of participants followed the AANEM/AAN/AAPM\&R Practice Parameter for Electrodiagnostic Studies in CTS. These guidelines are identical and have been adopted by all three organizations.

Lastly, we also asked how our respondents managed mild, moderate, and severe CTS. ${ }^{10}$ Again, respondents could use open text to answer this question.

\section{Statistical Methods}

Where appropriate, descriptive statistics were used to describe the electrodiagnostic tests performed and the management strategies they employed. Statistical comparisons using $\chi^{2}$ tests were made between these practice patterns and those recommended by the AANEM/AAN/AAPM\&R Practice Parameter for Electrodiagnostic 


\section{Table 2: Electrodiagnostic Studies Performed}

\begin{tabular}{|c|c|c|}
\hline & $\mathbf{N}$ & Percent \\
\hline \multicolumn{3}{|l|}{ Motor Studies } \\
\hline Median Motor Wrist & 68 & $97 \%$ \\
\hline Median Motor Forearm & 60 & $86 \%$ \\
\hline Median Motor Palm & 9 & $13 \%$ \\
\hline Median Motor Axilla & 1 & $1 \%$ \\
\hline Median Motor Erb's Point & 1 & $1 \%$ \\
\hline Lumbrical/2nd Interosseous Motor & 2 & $3 \%$ \\
\hline \multicolumn{3}{|l|}{ Sensory Studies } \\
\hline \multicolumn{3}{|l|}{ Median } \\
\hline D1 Median Sensory & 15 & $21 \%$ \\
\hline D2 Median Sensory & 50 & $71 \%$ \\
\hline D2 Segmental Sensory & 2 & $3 \%$ \\
\hline D3 Median Sensory & 25 & $36 \%$ \\
\hline D3 Segmental Sensory & 9 & $13 \%$ \\
\hline D4 Median Sensory & 30 & $43 \%$ \\
\hline \multicolumn{3}{|l|}{ Other } \\
\hline D1 Radial Sensory & 17 & $24 \%$ \\
\hline Snuff Box Radial Sensory & 16 & $23 \%$ \\
\hline D4 Ulnar Sensory & 30 & $43 \%$ \\
\hline D5 Ulnar Sensory & 61 & $87 \%$ \\
\hline Mixed Nerve Transpalmar Median/Ulnar & 21 & $30 \%$ \\
\hline Combined Sensory Index & 7 & $10 \%$ \\
\hline
\end{tabular}

Studies in CTS. Secondary comparisons examining practice patterns in academic vs. non-academic clinicians and clinician experience were made using the $\chi^{2}$, Kruskal Wallis, and t-tests. These were analyzed using R (version 3.0.0) and R Studio (version 0.97.336, Boston, Massachusetts) software programs.

\section{Results}

In total, 72 respondents $(31 \%)$ out of the 230 individuals contacted agreed to participate in the study. Of those who responded, 70 indicated which studies they performed routinely.

The respondents' demographics are described in Table 1. Based on years of practice, we had a good representation of differing experience levels. The majority of electromyographers performed EMG studies on one or two half day clinics per week. Seventy five percent (53/71) of our respondents were CSCN (Canadian Society of Clinical Neurophysiologists) certified members. Provincial representation was not statistically different compared with the Canadian population distribution $\left(\chi^{2}, \mathrm{P}=0.3633\right){ }^{11}$ Forty-four respondents $(62 \%)$ worked in an academic setting and 28 in a community setting.

\section{Electrodiagnostic Studies used in the Diagnosis of Carpal Tunnel Syndrome}

The most common test performed in the routine evaluation of CTS was the median motor study stimulating at the wrist and recording over the thenar eminence (97\%) (Table 2). The most common median sensory study, the antidromic digit two (D2) study, was routinely performed by $71 \%$ of respondents. This was followed by the digit four median/ulnar comparison study (43\%), and then by the digit three median sensory study $(36 \%)$. The median/ulnar mixed nerve transpalmar study was routinely performed by $30 \%$ of respondents. Median motor studies stimulating at Erb's point and in the axilla were rarely routinely done (1\%). The most common non-median test was the ulnar sensory digit five (D5) study $(87 \%)$. In total, only $16 \%$ indicated they performed needle EMG. When broken down according to CTS severity, $59 \%$ performed needle EMG in severe CTS and $25 \%$ in moderate CTS.

The most common standard distances used for each particular test and the percentage of clinicians who used these distances are presented in Table 3. For tests where there was a significant

Table 3: Most Common Fixed Distances Used

\begin{tabular}{l|c|c}
\hline & cm & Percent \\
\hline Digit 1 Radial Sensory & 10 & $83 \%$ \\
\hline Digit 2 Median Sensory & 14 & $61 \%$ \\
\hline Digit 3 Median Sensory & 14 & $71 \%$ \\
\hline Digit 4 Median Sensory & 14 & $84 \%$ \\
\hline Digit 4 Ulnar Sensory & 14 & $84 \%$ \\
\hline Digit 5 Ulnar Sensory & 14 & $43 \%$ \\
\hline Digit 5 Ulnar Sensory & 12 & $26 \%$ \\
\hline Mixed Nerve Transpalmar & 8 & $93 \%$ \\
\hline Digit 2 Segmental (Proximal Segment) & 7 & $67 \%$ \\
\hline Digit 2 Segmental (Distal Segment) & 7 & $67 \%$ \\
\hline Digit 3 Segmental (Proximal Segment) & & $71 \%$ \\
\hline Digit 3 Segmental (Distal Segment) & & 7 \\
\hline Median Motor Wrist & $7 \mathrm{~cm}$ from thenar eminence & $71 \%$ \\
\hline Median Motor Wrist & & $32 \%$ \\
\hline
\end{tabular}




\section{Table 4: Management by CTS Severity}

\begin{tabular}{l|c|c|c}
\hline Treatment Option & Mild & Moderate & Severe \\
\hline Splinting & $99 \%$ & $91 \%$ & $36 \%$ \\
\hline Steroid Injection & $23 \%$ & $33 \%$ & $10 \%$ \\
\hline Carpal Tunnel Surgery & $10 \%$ & $68 \%$ & $93 \%$ \\
\hline
\end{tabular}

amount of variability in the distances used by respondents, the two most commonly used distances are provided. For the digit five ulnar sensory testing, the two most commonly used distances were $14 \mathrm{~cm}(43 \%)$ or $12 \mathrm{~cm}(26 \%)$. For the median motor stimulation at the wrist, they were $8 \mathrm{~cm}$ from the thenar eminence in an L shape (32\%) or $7 \mathrm{~cm}$ from the thenar eminence in a straight line $(23 \%)$.

We questioned whether there was a difference in the number of nerve conduction studies performed routinely by academic versus community physicians. The mean number of tests performed by academic physicians was 6.1 (SD: 1.8) while community physicians performed a mean of 7.4 tests (SD: 3.4). The difference between these was not statistically significant (t-test, $\mathrm{p}=0.068$ ). There was no difference in the number of tests performed based on years of experience (Kruskal Wallis, $p=0.655$ ). Similarly, the number of tests performed routinely did not differ based on the time per week the clinician was practicing electromyography (Kruskal Wallis, $\mathrm{p}=0.2588$ ).

\section{Comparison of Responses to the AANEM/AAN/AAPM\&R Practice Parameter}

The practice parameter makes five recommendations around the appropriate electrodiagnostic studies to be used for the diagnosis of CTS and has categorized them as standards, guidelines, and options. Standards are accepted principles that reflect a high degree of clinical certainty. Guidelines are recommendations that reflect moderate clinical certainty. Options are strategies where the clinical utility is uncertain.

The first recommendation requires the use of a standard distance of $13-14 \mathrm{~cm}$ for the median sensory nerve conduction study. This was the standard most commonly not followed by clinicians, with $25 / 70$ (36\%) of those in our survey using a distance $<13 \mathrm{~cm}$. Ninety one percent of our participants satisfied the criteria for item 2 (Standard), that an additional study be performed besides the initial study in item 1 . We assumed that this criterion was met as long as one of the three recommended studies in item 2 was performed. With respect to item 3 (Guideline), the stipulation to perform a median motor conduction study with recording over the thenar muscle and one other nerve in the symptomatic limb, $99 \%$ of our participants performed this study. Item 4 outlines several supplementary nerve conduction studies that could be used as an "Option". Only 3\% performed the second lumbrical/second interosseous comparison study. Only $1 \%$ routinely followed item 5 (Option), the recommendation to perform needle electromyography of a sample of muscles innervated by the $\mathrm{C} 5$ to $\mathrm{T} 1$ spinal roots including a thenar muscle.

Overall, 36/70 (51\%) of participants followed the AANEM/ AAN/AAPM\&R clinical practice parameter regarding the electrodiagnostic studies performed.

\section{Management of Carpal Tunnel Syndrome}

Participants were also asked about management of CTS based on electrophysiological severity grading (Table 4). For mild carpal tunnel syndrome, the mainstay of treatment involved splinting (99\%) followed by steroid injection (23\%). Ten percent considered surgery as an option. For moderate carpal tunnel syndrome, splinting was recommended by $91 \%$ of clinicians while $68 \%$ would also consider surgery and $33 \%$ would consider steroid injection. For severe carpal tunnel syndrome, most recommended surgery (93\%) with wrist splints (36\%) or steroids $(10 \%)$ to be tried as a bridging measure while awaiting surgery. Other management techniques reported included ergonomic assessment (9\%), physiotherapy (3\%), mobilization/tendon gliding exercises (3\%), anti-inflammatories $(1 \%)$, active release therapy (1\%), vitamin B6 (1\%), and diuretics (1\%).

\section{DISCUSSION}

This study describes the variability in electrodiagnostic testing in Canada when attempting to confirm a diagnosis of CTS. In part, this is attributed to the breadth of available electrical studies to assess median nerve function. In an effort to standardize the electrodiagnosis of CTS, a number of organizations (AANEM/ AAN/AAPM\&R) in the United States (US) have adopted a practice parameter which directs the tests to be utilized when CTS is suspected. We observed that many Canadian electromyographers do not strictly adhere to these guidelines. There are a number of potential reasons for this. First, many clinicians may not be aware of the US-based practice parameter. Second, in several centres, nerve conduction studies are administered by EMG technologists who follow standard protocols that may have been put in place long before the most current practice parameter was developed in 2002. Third, many clinicians may feel that they are able to diagnose CTS accurately without strictly following the practice parameter. Fourth, some clinicians may question the importance of a fixed distance of $13 \mathrm{~cm}$ or $14 \mathrm{~cm}$ for sensory studies in the presence of existing well-defined normal values for other distances. ${ }^{9}$ Alternatively, they may have preferred to utilize conduction velocities with defined normal values rather than fixed distances. Fifth, billing in Canada is often not per nerve as can be the case in other countries. Lastly, if compressive median mononeuropathy is not established on routine testing, further electrodiagnostic studies are often carried out.

Our study raises the issue of whether Canadian guidelines for the diagnosis of CTS should be developed. Some clinicians already practise in a pattern consistent with the practice parameter laid out by the AANEM/AAN/AAPM\&R. These guidelines are evidence based, reasonable, and relatively easy to employ in the EMG clinic. Hence, there may not be a need for specific Canadian guidelines. Instead, what may be required is a more widespread endorsement of the practice parameter currently available and promotion of its use in Canada with a French translation. Key changes that would be required to optimize Canadian practice would include knowledge translation and dissemination of the practice parameter as well as our findings at national venues. It would also require buy in from EMG laboratories across the country, especially in EMG training centres.

With regard to treatment of CTS, while it appears the vast majority of clinicians suggest "mainstream" treatments for carpal tunnel syndrome (splints, surgery, steroid injection), a very small 
percentage still suggested alternative interventions. With respect to surgery, it is interesting that a greater percentage of our respondents recommended this intervention more often in severe cases compared to moderate or mild cases, especially considering that there is some evidence to suggest that patients with middlegrade abnormalities may have better outcomes than those with either very severe or no abnormality. ${ }^{12,13} \mathrm{Up}$ to $3 \%$ of clinicians would prescribe non-mainstream interventions which either had unknown effectiveness or were unlikely to be beneficial based on Ashworth's examination of the clinical evidence. ${ }^{14}$ The use of wrist splints, corticosteroid injections and surgery are all supported by Cochrane systematic reviews and should form the mainstay of clinical management in CTS. ${ }^{15-17}$

\section{Study Limitations}

Similar to many survey studies, there was the potential for bias with respect to our distribution method given that this was an email survey. In addition, as both the CNMG and the CAPM\&R Neuromuscular Special Interest Groups are not mandatory organizations for electromyographers in Canada, it is possible that those who are not members may have a different pattern of practice. There was also the possibility of respondent bias given our $31 \%$ response rate.

\section{Conclusion}

There appears to be considerable variability regarding which tests Canadian electromyographers perform to diagnose CTS. A large proportion of electromyographers do not strictly follow the AANEM/AAN/AAPM\&R Practice Parameter for electrodiagnostic testing in CTS. Variation also exists with respect to management of carpal tunnel syndrome. Future directions include encouraging Canadian clinicians to better adhere to AANEM/ AAN/AAPM\&R Practice Parameter and standardizing protocols across Canadian centres both for electrodiagnosis as well as management.

\section{DisClosures}

Rodney Li Pi Shan, Michael Nicolle, Ming Chan, Nigel Ashworth, Chris White and Paul Winston have nothing to disclose. Sean Dukelow has the following disclosures: Canadian Institutes of Health Research - Researcher, Grant support; Heart and Stroke Foundation - Researcher, Grant support.

\section{REFERENCES}

1. Rempel D, Evanoff B, Amadio PC, et al. Consensus criteria for the classification of carpal tunnel syndrome in epidemiologic studies. Am J Public Health. 1998;88:1447-51.

2. Atroshi I, Gummesson C, Johnsson R, Ornstein E, Ranstam J, Rosen I. Prevalence of carpal tunnel syndrome in a general population. JAMA. 1999;282:153-8.

3. Practice parameter for carpal tunnel syndrome (summary statement). Report of the Quality Standards Subcommittee of the American Academy of Neurology. Neurology. 1993;43:2406-9.

4. Pryse-Phillips WE. Validation of a diagnostic sign in carpal tunnel syndrome. J Neurol Neurosurg Psychiatry. 1984;47:870-2.

5. Katz JN, Larson MG, Sabra A, et al. The carpal tunnel syndrome: diagnostic utility of the history and physical examination findings. Ann Intern Med. 1990;112:321-7.

6. Jablecki CK, Andary MT, So YT, Wilkins DE, Williams FH. Literature review of the usefulness of nerve conduction studies and electromyography for the evaluation of patients with carpal tunnel syndrome. AAEM Quality Assurance Committee. Muscle Nerve. 1993;16:1392-414.

7. Practice parameter for electrodiagnostic studies in carpal tunnel syndrome: summary statement. Muscle Nerve. 2002;25:918-22.

8. Jablecki CK, Andary MT, Floeter MK, et al. Practice parameter: Electrodiagnostic studies in carpal tunnel syndrome. Report of the American Association of Electrodiagnostic Medicine, American Academy of Neurology, and the American Academy of Physical Medicine and Rehabilitation. Neurology. 2002;58:1589-92.

9. Kimura J. Electrodiagnosis in diseases of nerve and muscle principles and practice p133, p136. 3rd. ed. New York: Oxford University Press; 2001.

10. Stevens JC. AAEM minimonograph \#26: the electrodiagnosis of carpal tunnel syndrome. American Association of Electrodiagnostic Medicine. Muscle Nerve. 1997;20:1477-86.

11. http://en.wikipedia.org/wiki/List_of_Canadian_provinces_and_ territories_by_population.

12. Bland JD. Do nerve conduction studies predict the outcome of carpal tunnel decompression? Muscle Nerve. 2001;24: 935-40.

13. Malladi N, Micklesen PJ, Hou J, Robinson LR. Correlation between the combined sensory index and clinical outcome after carpal tunnel decompression: a retrospective review. Muscle Nerve. 2009;41:453-7.

14. Ashworth NL. Carpal tunnel syndrome. BMJ Clin Evid (Online). 2010.

15. Marshall S, Tardif G, Ashworth N. Local corticosteroid injection for carpal tunnel syndrome. Cochrane Database Syst Rev. 2007(2): CD001554.

16. Page MJ, Massy-Westropp N, O'Connor D, Pitt V. Splinting for carpal tunnel syndrome. Cochrane Database Syst Rev. 2012;7: CD010003.

17. Scholten RJ, Mink van der Molen A, Uitdehaag BM, Bouter LM, de Vet HC. Surgical treatment options for carpal tunnel syndrome. Cochrane Database Syst Rev. 2007(4):CD003905. 